\title{
Jurnal

\section{INTERVENSI EDUKASI BERBASIS THEORY OF PLANNED BEHAVIOR UNTUK MENINGKATKAN KEPATUHAN PENGOBATAN, NUTRISI, DAN PENCEGAHAN PENULARAN PADA PASIEN TUBERKULOSIS}

\section{Educational Intervention Based on Theory of Planned Behavior to Improve Compliance with Treatment, Nutrition, and Prevention of Transmission in Tuberculosis Patients}

\author{
Novian Mahayu Adiutama ${ }^{1}$, Ahmad Kholid Fauzi $^{2}$, Agusta Dian Ellina ${ }^{3}$
}

1. Universitas Qamarul Huda Badaruddin Bagu, Indonesia

2. Universiras Nurul Jadid, Indonesia

3. IIK STRADA Indonesia

\section{Riwayat artikel}

Diajukan: 4 maret 2021

Diterima: 11 Maret 2021

\section{Penulis Korespondensi:}

- Novian Mahayu

Adiutama

- Universitas Qamarul

Huda Badaruddin

Bagu, Indonesia

e-mail:

adiutama364@gmail.co

$\underline{\mathrm{m}}$

\section{Kata Kunci:}

Kepatuhan, Theory of Planned Behavior, Tuberkulosis

\section{Abstrak}

Perilaku kepatuhan pasien tuberkulosis menjadi faktor paling penting dalam mencapai keberhasilan pengobatan, termasuk kepatuhan terhadap obat-obatan, pencegahan penularan, dan kepatuhan nutrisi. Tujuan: Penelitian ini bertujuan untuk mengetahui pengaruh intervensi edukasi yang berbasis Theory Of Planned Behavior (TPB) dalam meningkatkan kepatuhan pasien TB. Metode: Quasy-experiment pre-post-test with control group dilakukan terhadap 108 pasien TB paru di Puskesmas Bubakan Pacitan, pengambilan sampel menggunakan teknik total sampling. Penelitian ini dilakukan dengan memberikan intervensi edukasi yang berbasis TPB pada kelompok intervensi selama 2 bulan. Analisis statistik penelitian ini menggunakan independen t-test dan chi-square. Hasil: Setelah dilakukan intervensi selama 2 bulan terdapat perbedaan signifikan di antara kelompok intervensi dan kontrol pada Attitude Toward Behavioral variables (ATB), Subjective Norm (SN), Percieved Behavior Control (PBC), niat, kepatuhan pengobatan, kepatuhan nutrisi, dan kepatuhan pencegahan penularan. Kesimpulan: Intervensi edukasi yang berbasis Theory Of Planned Behavior terbukti memiliki pengaruh dalam meningkatkan ATB, SN, PBC, niat, kepatuhan pengobatan, kepatuhan nutrisi, dan kepatuhan pencegahan penularan.

\footnotetext{
Abstract

Background: Adherence behavior of tuberculosis patients become the most crucial factor in achieving succes treatment, including adherence to compliance with medication, prevention of transmission, and nutritional compliance. Purpose: This study aims to determine the effect of educational intervention based on Theory of Planned Behavior (TPB) in improving adherence of TB patient. Methods: Quasy-experiment pre-post-test with control group were conducted on 108 patients with pulmonary tuberculosis in Puskesmas Bubakan Pacitan with purposive sampling technique. This study was conducted by educational interventions that based on TPB in the treatment groups for 2 months. The statistical test used was the independent t test and chi-square. Results: There were significant differences between treatment and control groups on attitude toward behavioral variables (ATB), subjective norm (SN), percieved behavior control (PBC), intention, medical adherence, prevention of transmission and nutritional compliance. Conclusion: Educational interventions that based on Theory of Planned Behavior proven to have an effect in improving the $A T B, S N, P B C$, intention, medical adherence, prevention of transmission, and nutrition compliance of TB patients.
} 


\section{PENDAHULUAN}

Tuberkulosis (TB) merupakan penyakit menular yang menjadi perhatian kesehatan dunia (Browne et al., 2018). Pengendalian tuberkulosis dengan strategi DOTS telah diterapkan di banyak negara sejak tahun 1995, namun hingga saat ini masih menjadi masalah global yang sulit diselesaikan (Adiutama, Amin and Bakar, 2018a).

Indonesia merupakan salah satu penyumbang tuberkulosis terbesar di dunia, menempati urutan kedua setelah India yaitu $10 \%$ dari seluruh penderita di dunia (WHO, 2015). Hal ini menjadi masalah yang sangat serius karena jangka waktu pengobatan yang lama dan membutuhkan kepatuhan yang tinggi dari pasien. Resistensi obat merupakan salah satu akibat dari kepatuhan pengobatan yang buruk, baik karena masalah dosis maupun kegagalan dalam menyelesaikan program pengobatan (GuixComellas et al., 2017). Rerata kepatuhan pasien dalam program pengobatan jangka panjang di negara maju hanya 50\%, sedangkan angka yang lebih rendah ditemukan di negara berkembang (WHO, 2015). Kepatuhan program pengobatan memiliki peran penting untuk mencegah penularan, kematian akibat TB, kekambuhan dan resistensi obat (Addisu $e t$ al., 2014).

Profil Kesehatan Indonesia 2015 menempatkan penyakit TB sebagai prioritas utama dalam pengendalian penyakit, kemungkinan karena penyakit TB berdampak luas terhadap kualitas hidup, ekonomi, serta tingginya kasus TB yang mengakibatkan kematian. Salah satu faktor yang sangat berpengaruh dalam upaya menekan atau mengendalikan kejadian TB adalah kepatuhan minum obat (Kemenkes RI, 2018). Pengukuran kepatuhan menjadi penting untuk mencapai keberhasilan pengobatan (Browne et al., 2018). Penderita TB dituntut memiliki kepatuhan yang tinggi terhadap program pengobatan sebagai upaya mengurangi beban TB. Oleh karena itu, penelitian ini dimaksudkan untuk mengukur kepatuhan pengobatan TB, kepatuhan nutrisi, dan kepatuhan pencegahan penularan. Penelitian ini menggunakan Theory of Planned Behavior (TPB) sebagai kerangka konseptual. Faktor utama TBP terbukti memiliki hubungan yang erat dengan niat (Miller et al., 2015). Konstruk TBP dapat memprediksi niat seseorang hingga terbentuk perilaku (Peleg et al., 2017). Jangka waktu pengobatan TB yang lama membutuhkan kepatuhan dan kestabilan niat yang tinggi dari pasien. Edukasi pengingkatan kepatuhan pasien TB berbasis Theory Of Planned Behavior (TPB) merupakan hal yang harus dilakukan guna memelihara niat pasien TB untuk berperilaku patuh.

Berdasarkan hal tersebut, penulis menawarkan intervensi dengan menggabungkan pengingat keperawatan interaktif berbasis SMS dan edukasi tatap muka guna menjaga kestabilan intensi pasien TB dalam mematuhi proses pengobatan menggunakan pendekatan Theory of Planned Behavior, perilaku patuh yang dimaksud meliputi pengobatan, nutrisi, dan pencegahan penularan. Dalam penelitian ini, kami mengeksplorasi pengaruh intervensi edukasi yang berbasis Theory of Planned Behavior (TPB) dalam meningkatkan kepatuhan pasien TB.

\section{METODE}

Quasy-experiment pre-post-test with control group dilakukan pada pasien tuberkulosis paru dengan tes AFB positif (Acid-Fast Bacilli) di sebuah Puskesmas yang terletak di Kabupaten Pacitan $(\mathrm{N}=$ 108). Kriteria sampel kelompok intervensi dan kontrol disamakan untuk menjaga kesetaraan karakteristik di antara kedua kelompok, pasien yang direkrut untuk menjadi responden adalah pasien yang memiliki ponsel dan dapat 
mengoperasikannya, menggunakan komunikasi Bahasa Indonesia, pasien dalam tahap pengobatan intensif, dan pasien dengan status pendidikan dasar 9 tahun. Pasien dengan gangguan muskuluskeletal, pendengaran, kesehatan mental, komplikasi akut, dan pasien yang mengganti nomor telepon pada saat penelitian akan dikeluarkan dari penelitian ini. Rekrutmen responden menggunakan metode total sampling. Pengumpulan data dilakukan mulai tanggal 1 Juni hingga 1 Agustus 2020. Penelitian ini dilakukan dengan melakukan intervensi edukasi berbasis TPB pada kelompok perlakuan selama 2 bulan. Terdapat kombinasi interactive nursing reminder untuk mengirimkan pesan pengingat melalui SMS (Short Message System) 2 kali sehari selama 2 bulan, dan edukasi keperawatan tatap muka dilakukan sebanyak 4 kali. Protokol penelitian ini telah disetujui oleh Komisi Etik Penelitian Kesehatan STIKES Buleleng dengan nomor etik: 114/EC-KEPK-SB/V/2020.

Penelitian ini menggunakan kuesioner sebagai instrument pengumpulan data. Kepatuhan pengobatan diukur menggunakan MMAS-8 (Morrisky Medication Adherence Scale-8) (Morisky et al., 2008), pencegahan penularan dan kepatuhan nutrisi diukur menggunakan kuesioner dari Sukartini et al. (2015), sedangkan ATB, SN, PBC, dan Intention diukur menggunakan instrumen yang dikembangkan dari instrumen standar TPB.

Independent t-test digunakan untuk menganalisis perbedaan ATB, SN, PBC, Niat, Keptuhan Pengobatan, Kepatuhan Nutrisi, dan Kepatuhan Pencegahan Penularan di antara kedua kelompok setelah intervensi edukasi berbasis teori perilaku terencana. Tingkat signifikansi yang ditentukan adalah $\mathrm{p}<0,05$.

\section{HASIL DAN PEMBAHASAN HASIL}

Karakteristik sosio demografi pada tabel 1 menunjukkan sebanyak 108 responden dalam penelitian ini memberikan respon $100 \%$. Berdasarkan hasil uji chisquare menunjukkan bahwa tidak terdapat perbedaan karakteristik responden pada jenis kelamin, umur, dan status perkawinan dengan nilai $\mathrm{p}>0,05$ artinya kedua kelompok adalah setara atau sederajat.

Tabel 1 Karakteristik Demografi $(\mathrm{n}=108)$

\begin{tabular}{|c|c|c|c|c|c|}
\hline & \multicolumn{4}{|c|}{ Kelompol } & \multirow{3}{*}{$\begin{array}{c}\mathrm{P} \\
\text { value }\end{array}$} \\
\hline & \multicolumn{2}{|c|}{$\begin{array}{c}\text { Intervensi } \\
(\mathrm{n}=54)\end{array}$} & \multicolumn{2}{|c|}{$\begin{array}{c}\text { Kontrol } \\
(\mathrm{n}=54)\end{array}$} & \\
\hline & $\mathrm{n}$ & $\%$ & $\mathrm{n}$ & $\%$ & \\
\hline \multicolumn{6}{|l|}{ Jenis Kelamin } \\
\hline Pria & 32 & 65,6 & 28 & 53,1 & \multirow{2}{*}{0,309} \\
\hline Wanita & 22 & 34,4 & 26 & 46,9 & \\
\hline \multicolumn{6}{|l|}{ Usia } \\
\hline $15-45$ & 29 & 56,3 & 30 & 59,4 & \multirow{2}{*}{0,801} \\
\hline $45-60$ & 25 & 43.7 & 24 & 40,6 & \\
\hline \multicolumn{6}{|l|}{ Pekerjaan } \\
\hline Bekerja & 27 & 81,3 & 29 & 56,3 & \multirow[b]{2}{*}{0,061} \\
\hline $\begin{array}{l}\text { Tidak } \\
\text { Bekerja }\end{array}$ & 21 & 18,7 & 25 & 43,7 & \\
\hline \multicolumn{6}{|l|}{ Status } \\
\hline \multicolumn{6}{|l|}{ Perkawinan } \\
\hline Kawin & 18 & 56,3 & 17 & 53,1 & \multirow[b]{2}{*}{0,802} \\
\hline $\begin{array}{l}\text { Tidak } \\
\text { Kawin }\end{array}$ & 14 & 43,7 & 15 & 46,7 & \\
\hline
\end{tabular}

Sumber: Data Primer Tahun 2020

Perbedaan nilai delta antar variabel dependen diuji menggunakan independent ttest. Hasil uji beda nilai delta ATB, SN, PBC, niat, kepatuhan minum obat, kepatuhan pencegahan penularan, dan kepatuhan nutrisi pada kedua kelompok dapat dilihat pada tabel 2. Hasil uji independent $\mathrm{t}$-test menunjukkan terdapat perbedaan nilai delta yang signifikan di antara kedua kelompok pada variabel ATB, $\mathrm{SN}, \mathrm{PBC}$, niat, kepatuhan minum obat, kepatuhan pencegahan penularan, dan kepatuhan nutrisi pasien tuberkulosis, dengan nilai signifikansi $(\mathrm{p}<0,05)$. 
Tabel 2 Hasil Uji Beda Nilai Delta pada Seluruh Variabel

\begin{tabular}{lccccc}
\hline \multirow{2}{*}{ Variable } & \multicolumn{4}{c}{ Group } & \multirow{2}{*}{ P } \\
\cline { 2 - 5 } & \multicolumn{2}{c}{ Treatment } & \multicolumn{2}{c}{ Control } & value \\
\cline { 2 - 5 } & delta & SD & delta & SD & \\
\hline ATB & 18 & 19,16 & 0,19 & 6,83 & 0,04 \\
SN & 13,5 & 17,89 & 0,13 & 2,24 & 0,03 \\
PBC & 15,8 & 18,85 & 0,28 & 8,37 & 0,02 \\
Niat & 2,84 & 2,85 & 0,03 & 1,09 & 0,01 \\
Kepatuhan & 1,38 & 1,07 & 0,19 & 0,592 & 0,02 \\
Pengobatan & & & & & \\
Kepatuhan & 2,22 & 2,41 & 0,19 & 0,693 & 0,02 \\
$\begin{array}{l}\text { Nutrisi } \\
\text { Pencegahan }\end{array}$ & 3,25 & 2,907 & 0,34 & 1,31 & 0,01 \\
Penularan & & &
\end{tabular}

Sumber: Data Primer Tahun 2020

\section{PEMBAHASAN}

1. Attitude Toward Behavioral

Hasil penelitian menunjukkan adanya pengaruh intervensi edukasi berbasis Theory of Planned Behavioral terhadap Attitude Toward Behavioral pasien TB. Setelah mendapatkan intervensi edukasi berbasis Theory of Planned Behavior nilai Attitude Toward Behavioral pasien TB meningkat. Peningkatan tersebut dapat dicapai dengan membentuk sikap positif terhadap pengobatan tuberkulosis dengan pendekatan beliefs, dengan intervensi rutin 2 bulan dimana peneliti dan pasien berinteraksi tatap muka sebanyak 4 kali dan mengirimkan pesan pengingat secara intensif setiap 2 hari sekali pasien memperoleh keyakinan bahwa ia dapat dan mampu menjalani terapi tuberkulosis yang sulit.

Hasil penelitian ini sejalan dengan penelitian lain tentang pendidikan dalam mempromosikan kepatuhan TB berbasis beliefs, penelitian yang dilakukan pada 68 pasien TB di Barcelona mengungkapkan bahwa pendidikan berbasis keyakinan sangat efektif dalam membangun sikap yang mendukung perilaku kepatuhan pengobatan (Guix-
Comellas et al., 2017). Meta analisis tentang intervensi pengobatan penyakit kronis menyimpulkan bahwa intervensi yang berbasis beliefs lebih berdampak positif pada sikap dan perilaku kepatuhan itu sendiri (Rich et al., 2015). Studi konseling lainnya selama pengobatan tuberkulosis di Rio de Janeiro memberikan gambaran bahwa sikap yang berbasis beliefs lebih langgeng daripada sikap yang terbentuk dari rekomendasi medis (Costa et al., 2017).

\section{Subjective Norm}

Secara statistik intervensi edukasi berbasis Theory of Planned Behavior terbukti mempengaruhi norma subjektif (Subjective Norm) penderita tuberkulosis. Sebelum dilakukan intervensi nilai norma subyektif pada kelompok kontrol dan kelompok intervensi tidak jauh berbeda, namun setelah intervensi 2 bulan terlihat adanya perbedaan nilai. Kelompok intervensi cenderung lebih menunjukkan peningkatan nilai norma subjektif yang signifikan, intervensi edukasi berbasis Theory of Planned Behavior terbukti menimbulkan persepsi positif terhadap tekanan sosial atau sejumlah orang yang dianggap penting dalam mengadvokasi pengobatan, sedangkan dalam kelompok kontrol meskipun mereka mengalami meningkat tetapi peningkatannya tidak signifikan secara statistik. Peningkatan pada kelompok intervensi dapat dicapai dengan interaksi rutin melalui edukasi tatap muka sebanyak 4 kali dengan keluarga pasien, dan penyampaian pesan reminder 2 kali sehari selama 2 bulan.

Hasil penelitian lain tentang edukasi dalam mempromosikan kepatuhan tuberkulosis pada 68 pasien TB di Barcelona menegaskan bahwa 
pendidikan berbasis keyakinan efektif dalam menetapkan norma subjektif yang mendukung pengobatan pasien tuberculosis (Guix-Comellas et al., 2017). Sebuah studi yang hampir identik tentang kepatuhan pengobatan tuberkulosis menyimpulkan bahwa intervensi sosial dan psikologis harus dioptimalkan untuk meningkatkan kepatuhan pengobatan dengan pasien TB (Yan et al., 2018). Kepatuhan terhadap pengobatan yang baik dapat dicapai dengan memanfaatkan pengaruh sosial melalui pendidikan anggota keluarga tentang bagaimana mendukung kepatuhan pengobatan pada kerabatnya yang sakit (Kopelowicz et al., 2015). Studi meta analisis tentang intervensi kepatuhan pengobatan pada penyakit kronis juga mengungkapkan bahwa intervensi yang menggunakan pendekatan kepercayaan akan memberikan efek yang lebih lama (Rich et al., 2015). Studi lain tentang kepatuhan pasien tuberkulosis di Afrika Selatan menegaskan bahwa dukungan sosial yang baik terbukti meningkatkan kepatuhan pada pasien TB (Akeju, Wright and Maja, 2017).

\section{Perceived Behavior Control}

Hasil penelitian menunjukkan bahwa intervensi edukasi berbasis Theory of Planned Behavior memiliki pengaruh yang signifikan dalam meningkatkan persepsi perilaku (Perceived Behavior Control) pasien tuberkulosis, intervensi edukasi ini dapat membantu pasien TB dalam meningkatkan persepsi positif tentang mudah atau tidaknya menjalani proses pengobatan. Peningkatan terlihat pada kelompok intervensi setelah dilakukan edukasi tatap muka sebanyak 4 kali dan pesan pengingat sebanyak 2 kali sehari selama 2 bulan, sedangkan pada kelompok kontrol tidak ditemukan peningkatan.

Penelitian ini didukung oleh studi tentang edukasi dalam mempromosikan kepatuhan penderita tuberkulosis bahwa pendidikan berbasis keyakinan efektif dalam meningkatkan kontrol perilaku perseptif pasien tuberkulosis dalam menyelesaikan pengobatan (Vervloet et al., 2012). Pengendalian perilaku yang dipersepsikan dalam penelitian ini adalah tentang persepsi seseorang mengenai mudah atau tidaknya seorang individu untuk melakukan perilaku dan merupakan cerminan dari pengalaman sebelumnya dan hambatan yang dapat diantisipasi. Semakin banyak faktor pendukung dan sedikit faktor penghambat yang dirasakan individu untuk dapat melakukan suatu perilaku maka semakin besar pula kontrol yang mereka rasakan terhadap perilaku tersebut dan sebaliknya. Konsepsi ditentukan oleh keyakinan seseorang atau disebut juga keyakinan kontrol untuk mengontrol faktor - faktor yang menghambat atau mendorong munculnya suatu perilaku (Mcdermott et al., 2015).

4. Niat

Secara statistik, intervensi edukasi berbasis Theory of Planned Behavior terbukti mempengaruhi niat pasien tuberkulosis untuk mematuhi pengobatan, nurtrisi, dan pencegahan penularan. Sebelum dilakukan intervensi nilai intensi pada kelompok kontrol dan kelompok intervensi tidak jauh berbeda, namun setelah dilakukan intervensi selama 2 bulan terlihat perbedaan nilai yang signifikan. Kelompok intervensi cenderung semakin meningkatkan nilai niat dalam mematuhi pengobatan, nurtrisi, dan pencegahan penularan. Sedangkan pada kelompok kontrol meskipun mengalami 
peningkatan namun peningkatannya tidak signifikan secara statistik. Peningkatan yang signifikan pada kelompok intervensi dapat dicapai dengan interaksi rutin melalui tatap muka edukasi sebanyak 4 kali dengan keluarga pasien, dan penyampaian pesan reminder 2 kali sehari selama 2 bulan.

Hasil penelitian ini hampir identik dengan penelitian yang dilakukan di University of Pennsylvania Hospital yang melaporkan bahwa pesan pengingat terbukti efektif dalam mempertahankan niat meminum dosis (Reese et al., 2016). Studi serupa lainnya menyatakan bahwa pasien penyakit kronis yang menggunakan reminder menunjukkan kepatuhan, sistem reminder berguna untuk meningkatkan niat kepatuhan, sikap kepatuhan, perilaku kepatuhan, dan manajemen diri. Pasien yang menggunakan sistem reminder dalam pengobatannya akan mendapatkan dukungan dan manfaat langsung (Foster et al., 2017).

Sebuah studi sebelumnya tentang niat dalam Theory of Planned Behavior menjelaskan bahwa niat dan Perilaku dalam konteks Theory of Planned Behavior dapat menjelaskan niat dan perilaku penganut pengobatan. Kepatuhan dalam pengobatan juga tergantung pada orientasi pribadi individu itu sendiri. Model pendidikan kognitif yang dimoderasi dengan konstruksi TPB terbukti efektif dalam menjaga niat dan perilaku kesehatan seseorang (Peleg et al., 2017). Hasil penelitian di atas juga didukung oleh penelitian yang menyatakan bahwa penyuluhan kesehatan dengan menggunakan SMS reminder terbukti meningkatkan niat dan perilaku kepatuhan pasien dalam proses pengobatan, dan SMS reminder juga dapat diterima dengan baik oleh pasien (Akeju, Wright and Maja, 2017).

5. Kepatuhan Pengobatan

Hasil penelitian menunjukkan bahwa intervensi edukasi berbasis Theory of Planned Behavior berpengaruh signifikan terhadap peningkatan kepatuhan pengobatan pasien tuberkulosis. Setelah mendapatkan intervensi edukasi berbasis Theory of Planned Behavior, pada kelompok intervensi terlihat mengalami peningkatan kepatuhan minum obat yang signifikan. Pengaruh kepatuhan minum obat diperoleh dengan intervensi rutin selama 2 bulan dimana peneliti, pasien, dan keluarga berinteraksi tatap muka sebanyak 4 kali, serta dengan mengirimkan pesan reminder (Interactive Nursing Reminder) secara intensif 2 kali sehari selama 2 bulan, sehingga kepatuhan terhadap subjek yang telah terbentuk dapat diwujudkan atau dimunculkan sebagai perilaku yang konsisten. Kepatuhan ini meningkat dikarenakan responden merasa puas dengan perilaku caring perawat yang selalu mengingatkan dan mengedukasi setiap hari. Caring merupakan hal utama yang digunakan oleh pelayanan kesehatan untuk mencapai kepuasan pasien (Ellina et al., 2019).

$$
\text { Hasil penelitian serupa }
$$
menunjukkan bahwa metode reminder dapat digunakan sebagai metode alternatif untuk membantu pasien mencapai kepatuhan dalam menjalani pengobatan yang panjang dan menjenuhkan (Reese et al., 2016). Uji coba kontrol acak mengungkapkan gagasan bahwa metode pengingat efektif dalam meningkatkan kepatuhan pengobatan (Dai et al., 2017). Short Message System (SMS) sangat efektif dalam meningkatkan kepatuhan pasien 
terhadap obat (Akeju, Wright and Maja, 2017). Pendapat tersebut juga didukung oleh penelitian yang menyatakan bahwa penyuluhan kesehatan dengan menggunakan SMS reminder terbukti dapat meningkatkan kepatuhan pasien dalam proses pengobatan dan SMS reminder juga dapat diterima dengan baik oleh pasien (Vervloet et al., 2012).

6. Kepatuhan Nutrisi

Secara statistik intervensi edukasi berbasis Theory of Planned Behavior berpengaruh signifikan terhadap peningkatan kepatuhan nutrisi penderita tuberkulosis. Peningkatan ini diperoleh dengan melakukan edukasi tatap muka tentang nutrisi yang direkomendasikan, dan menumbuhkan keyakinan responden bahwa nutrisi yang baik dapat berdampak positif pada proses pengobatan. Edukasi ini didukung dengan system pesan pengingat yang berisi makan 3 kali per hari, nafsu makan untuk menghindari fast food dan makanan pemicu batuk, seperti pemanis buatan, dan makanan berminyak. Peningkatan kepatuhan nutrisi juga ditemukan pada kelompok kontrol, namun peningkatan yang ditemukan tidak bermakna secara statistik, hal ini dapat disebabkan oleh pendidikan petugas kesehatan dan banyaknya poster makanan yang direkomendasikan di lokasi penelitian.

Hasil penelitian serupa lainnya menunjukkan bahwa pasien penyakit kronis yang menggunakan reminder menunjukkan kepatuhan, sistem pengingat yang berguna untuk meningkatkan sikap kepatuhan, perilaku kepatuhan, dan manajemen diri (Malek et al., 2017). Pasien yang menggunakan sistem reminder dalam pengobatannya akan mendapatkan dukungan dan manfaat langsung (Foster et al., 2017). Studi pendukung lain tentang nutrisi atau kepatuhan diet pada penyakit kronis menunjukkan bahwa Sistem Pesan Singkat (SMS) sangat efektif dalam meningkatkan kepatuhan pasien terhadap diet dan pengobatan (Akhu-zaheya and Shiyab, 2017).

7. Kepatuhan Pencegahan Penularan

Hasil penelitian menunjukkan adanya pengaruh intervensi edukasi berbasis Theory of Planned Behavior dalam meningkatkan kepatuhan pencegahan penularan pada pasien tuberkulosis. Pada penelitian ini pada kelompok kontrol juga mengalami peningkatan namun secara statistic peningkatan tersebut tidak bermakna, hal ini bisa disebabkan kelompok kontrol juga diinformasikan tentang pencegahan penularan melalui promosi kesehatan di pelayanan kesehatan setempat. Peningkatan pencegahan infeksi pada kelompok intervensi diperoleh melalui edukasi tatap muka tentang pencegahan penularan dan penjelasan lingkungan yang mendukung pencegahan penularan, didukung dengan interactive nursing reminder yang secara intensif mengingatkan pentingnya pencegahan penularan. Dalam intervensi ini responden diberikan pemahaman tentang cara batuk dan bersin yang benar, cara membuang dahak, penggunaan alat makan dan minum, serta lingkungan rumah agar tidak tertular.. Pendekatan belief dapat mendorong individu untuk menampilkan atau melakukan perilaku tertentu.

Intervensi edukasi berbasis Theory of Planned Behavior mengarahkan pasien tentang bagaimana cara berinteraksi dengan lingkungannya agar pasien mengetahui bagaimana mencegah penularan infeksi dan tidak merugikan orang lain di sekitarnya, 
pasien juga diajarkan bagaimana lingkungan yang sehat agar tidak terjadi penularan. Seiring dengan terbentuknya niat dan pemahaman tentang pencegahan penularan, pesan reminder dikirim secara intensif agar niat dan pemahaman dapat diubah menjadi perilaku yang konsisten, sehingga pasien mampu menerapkan pencegahan penularan baik di rumah sakit, di rumah dan saat berinteraksi dengan lingkungan sosial (Adiutama, Amin and Bakar, 2018b)

\section{KESIMPULAN}

Tidak terdapat perbedaan karakteristik responden pada jenis kelamin, usia, pekerjaan, dan status perkawinan dengan nilai $p>0,05$, artinya kedua kelompok sama atau setara. Intervensi edukasi yang berbasis Theory of Planned Behavior terbukti berpengaruh dalam meningkatkan ATB, $\mathrm{SN}, \mathrm{PBC}$, niat, kepatuhan pengobatan, pencegahan penularan, dan kepatuhan nutrisi pasien TB.

Perlu dilakukan penelitian lanjutan di pelayanan kesehatan dengan responden TBMDR. Perancangan desain prototipe interactive nursing remainder juga harus dilakukan karena walaupun interactive nursing remainder mempunyai manfaat langsung dalam menjaga kestabilan niat dan konsistensi kepatuhan program pengobatan tuberkulosis, namun penerapan sistem reminder melalui SMS masih memiliki kelemahan dan perlu diperhatikan karena pesannya tidak dapat memastikan apakah pasien benar-benar mematuhi pesan tersebut atau tidak.

\section{ACKNOWLEDGMENT}

Studi ini merupakan bagian dari proyek yang berjudul "Intervensi Edukasi Berbasis Theory of Planned Behavior untuk Meningkatkan Kepatuhan Pengobatan, Diet, dan Pencegahan Penularan pada Pasien Tuberkulosis", yang didanai oleh
Direktorat Riset dan Pengabdian Masyarakat, Direktorat Jendral Penguatan Riset dan Pengembangan Kementerian Riset, Teknologi, dan Pendidikan Tinggi Republik Indonesia.

\section{CONFLICTS OF INTEREST}

Tidak ada conflicts of interest

\section{DAFTAR PUSTAKA}

Addisu, Y. et al. (2014) 'Predictor Of Treatment Seeking Intention Among People With Cough In East Wollega, Ethiopia Based On The Theory Of Planned Behavior: A Community Based Cross-Sectional Study', Ethiop J Health Sci, 24(2). doi: http://dx.doi.org/10.4314/ejhs.v24i2.5.

Adiutama, N. M., Amin, M. and Bakar, A. (2018a) 'An Evaluation of Medication Adherence in Tuberculosis Patients Based on Theory of Planned Behavior', in Proceedings of the 9th International Nursing Conference. Surabaya: SCITEPRESS - Science and Technology Publications, pp. 428-434. doi: 10.5220/0008326204280434.

Adiutama, N. M., Amin, M. and Bakar, A. (2018b) Pengaruh Intervensi Edukasi Berbasis Theory Of Planned Behavior dalam Meningkatkan Kepatuhan Pasien Tuberkulosis. Universitas Airlangga.

Akeju, O. O., Wright, S. C. D. and Maja, T. M. (2017) 'Lived experience of patients on tuberculosis treatment in Tshwane, Gauteng province', Health SA Gesondheid. Elsevier Ltd, 22, pp. 259267. doi: 10.1016/j.hsag.2017.03.001.

Akhu-zaheya, L. M. and Shiyab, W. Y. (2017) 'Informatics The effect of short message system ( SMS ) reminder on adherence to a healthy diet, medication , and cessation of smoking among adult patients', International Journal of 
Medical Informatics. Elsevier Ireland Ltd, 98, pp. 65-75. doi: 10.1016/j.ijmedinf.2016.12.003.

Browne, S. H. et al. (2018) 'Digitizing Medicines for Remote Capture of Oral Medication Adherence Using Coencapsulation', Clinical Pharmacology and Therapeutics, 103(3), pp. 502-510. doi: 10.1002/cpt.760.

Costa, A. et al. (2017) 'Clinical Nutrition ESPEN Dietary counseling adherence during tuberculosis treatment: A longitudinal study', Clinical Nutrition ESPEN, 17, pp. 44-53. doi: 10.1016/j.clnesp.2016.11.001.

Dai, H. et al. (2017) 'The effect of interactive reminders on medication adherence: A randomized trial', Preventive Medicine. Elsevier Inc. doi: 10.1016/j.ypmed.2017.07.019.

Ellina, A. D. et al. (2019) 'Evaluation of patient satisfaction and nurse caring behaviour: Based on swanson's theory', Indian Journal of Public Health Research and Development, 10(8), pp. 2698-2702. doi: 10.5958/0976-5506.2019.02277.0.

Foster, J. M. et al. (2017) 'Patient-perceived acceptability and behaviour change bene fi ts of inhaler reminders and adherence feedback: A qualitative study', Respiratory Medicine. Elsevier Ltd, 129, pp. 39-45. doi: 10.1016/j.rmed.2017.05.013.

Guix-Comellas, E. M. et al. (2017) 'Educational Measure for Promoting Adherence to Treatment for Tuberculosis', Procedia - Social and Behavioral Sciences. The Author(s), 237(June 2016), pp. 705-709. doi: 10.1016/j.sbspro.2017.02.047.

Kemenkes RI (2018) Profile Kesehatan Indonesia Tahun 2018, Ministry of Health Indonesia. Indonesia. doi:

\subsection{2/qj.}

Kopelowicz, A. et al. (2015) 'Using the Theory of Planned Behavior to Improve Treatment Adherence in Mexican Americans With Schizophrenia.', J Consult Clin Psychol, 83(5), pp. 985993. doi: 10.1037/0022006X.76.1.104.

Malek, L. et al. (2017) 'Predicting healthy eating intention and adherence to dietary recommendations during pregnancy in Australia using the Theory of Planned Behaviour', Appetite. Elsevier Ltd, 116, pp. 431441. doi: 10.1016/j.appet.2017.05.028.

Mcdermott, M. S. et al. (2015) 'The Theory of Planned Behaviour and dietary patterns: A systematic review and meta-analysis', Preventive Medicine. Elsevier Inc., 81, pp. 150-156. doi: 10.1016/j.ypmed.2015.08.020.

Miller, J. et al. (2015) 'Applying The Theory of Planned Behavior to Understand Plate Waste of Elementry School Student', Proquest LLC.

Morisky, D. E. et al. (2008) 'Predictive validity of a medication adherence measure in an outpatient setting', Journal of Clinical Hypertension, 10(5), pp. 348-354. doi: 10.1111/j.1751-7176.2008.07572.x.

Peleg, S. et al. (2017) 'Attachment Orientation Moderates Theory of Planned Behavior Prediction of Cardiac Medication Adherence', Journal of Personality, pp. 1-42. doi: 10.1111/jopy.12294.

Reese, P. P. et al. (2016) 'Automated Reminders and Physician Notification to Promote Immunosuppression Adherence Among Kidney Transplant Recipients: A Randomized Trial', American Journal of Kidney Diseases. Elsevier

Inc. 
10.1053/j.ajkd.2016.10.017.

Rich, A. et al. (2015) 'Theory of planned behavior and adherence in chronic illness: a meta-analysis', Journal of Behavioral Medicine. Springer US. doi: 10.1007/s10865-015-9644-3.

Sukartini, T. et al. (2015) 'Adherence in Pulmonary Tuberculosis Patients Based on King's Interacting Systems Theory', Ners Journal, 10, pp. 289-295.

Vervloet, M. et al. (2012) 'SMS reminders improve adherence to oral medication in type 2 diabetes patients who are real time electronically', International Journal of Medical Informatics. Elsevier Ireland Ltd, 81(9), pp. 594604. doi: 10.1016/j.ijmedinf.2012.05.005.

WHO (2015) Global Tuberculosis Report. 20th edn. France: WHO Library Cataloguing-in-Publication Data.

Yan, S. et al. (2018) 'Nonadherence to Antituberculosis Medications: The Impact of Stigma and Depressive Symptoms', The American Journal of Tropical Medicine and Hygiene, 98, p. 4269. doi: 10.4269/ajtmh.17-0383. 